\title{
CRASH E O NOVO PARADIGMA DA VIOLÊNCIA
}

Ms. Yuri Michael Pereira Costa

(Professor do Departamento de História e Geografia da UEMA. Conselheiro Estadual de Defesa dos Direitos Humanos do Maranhão).

Resumo: Análise do chamado "novo paradigma da violência", que inaugura conceitos e premissas de interpretação de atos de violência, tendo como pano de fundo uma possível leitura do filme Crash (2004). Destaca-se a crítica advinda, após o atentado de 11 de setembro, ao cotidiano de intolerância e preconceito que marca a sociedade norteamericana.

Palavras-chave: Violência, Intolerância, Terrorismo, Crash.

Abstract: Analysis the called "new paradigm of violence", which open concepts and premises about violence acts interpretations, with fundament in a possible lecture of the film Crash (2004). To eminence a review happened, after the September 11 attempt, to the daily of intolerance and prejudice which mark the north-American society.

Key-words: Violence, Intolerance, Terrorism, Crash

\section{INTRODUÇÃO}

A idéia de que as últimas décadas do século $\mathrm{XX}$ conheceram um crescimento sem precedentes de atos de violência tornou-se lugar comum entre parte dos sociólogos que escreveram no fim do referido século. Um dos pontos de apoio dessa interpretação é a noção de "ruptura". Mais do que os desdobramentos de uma "longa duração", marcada por formas extremadas de resolução de conflitos, uma mudança radical de práticas e representações sobre a violência, ocorrida no último quartel do século XX, demandaria um novo olhar sobre os atos violentos.

Tal vertente interpretativa, percebendo o século XXI como herdeiro desta "ruptura", constitui uma das teorias explicativas da violência contemporânea, surgindo, assim, como novo paradigma de inteligibilidade da violência. 
O objetivo deste artigo é, dialogando com uma possível leitura do filme Crash: no limite $^{1}$, produção hollywoodiana de 2004, escrita e dirigida por Paul Haggis, tecer comentários sobre o chamado "novo paradigma da violência", que procura estabelecer novos conceitos e princípios de inteligência de fenômenos ligados à violência. ${ }^{2}$

Quando de sua produção, os idealizadores de Crash não pretendiam, até pelo baixo custo da obra, se comparado a superproduções de Hollywood, ter grande destaque em premiações. Contrariando as expectativas, o filme concorreu a seis Oscars, em 2006, ganhando três deles, incluindo o de melhor filme. O sucesso, em premiações e bilheteria, foi interpretado, por diferentes críticos de cinema, como derivado do principal objeto de crítica da obra: a "confusão ideológica" que se instalou na sociedade norte-americana pós11 de setembro, caracterizada pela radicalização de preconceitos e pelo aumento da intolerância.

O filme retrata o cotidiano de personagens, cujas vidas, aparentemente, não possuem conexão. Tem como cenário a cidade de Los Angeles (Califórnia) e se desenvolve no ano de 2004, num espaço de tempo não maior que 36 horas. Um Promotor Público e sua esposa, um casal de detetives, dois policiais, um casal coreano, um chaveiro mexicano, um lojista iraniano, uma dupla de assaltantes negros, dentre outros, são os personagens do filme.

As relações entre os diferentes personagens, iniciadas por conflitos aparentemente sem maior expressão, servem como pano de fundo para o extravasamento de preconceitos e intolerâncias que se irradiam em inúmeras direções, ligando-se, em diferentes intensidades, principalmente, à imigração e à questão racial.

\section{ESVAZIAMENTO IDEOLÓGICO OU A MORTE CONTRA A MORTE}

\footnotetext{
${ }^{1}$ O nome do filme é uma onomatopéia (“crash”) que representa, no caso, a batida entre veículos. O filme se inicia com uma colisão entre o carro onde estavam os detetives Graham (Don Cheadle) e Ria (Jennifer Esposito) e o veiculo dirigido pela coreana Kim Lee (Alexis Rhee). Da mesma forma, o filme termina com outro acidente, agora envolvendo o carro da atendente Shaniqua (Loretta Devide).

2 Essa vertente "paradigmática" será aqui representada por autores como Michel Wieviorka, Hans Magnus Enzensberger, Jean Baudrillard, Michel Mafessoli, Michael Hardt e Antonio Negri.
} 
Mesmo de difícil datação, o marco em regra, utilizado na identificação do início do novo paradigma da violência são as décadas de 60 e 70, período que inauguraria uma nova "era”, um novo "ciclo" de manifestações violentas.

As transformações recentes, a partir dos anos 60 e 70, são tão consideráveis, que justificam explorar-se a idéia da chegada de uma nova era, e, assim, de um novo paradigma da violência, que caracterizaria o mundo contemporâneo (WIEVIORKA, 1997, p. 5).

Um dos critérios utilizados na identificação das décadas de 60/70 como "paradigmáticas" é a re-significação que tal período trouxe aos conceitos de "bem" e "mal". Nesse contexto, haveria a relativização da noção de que, atos tidos como violentos, associam-se, necessariamente, à idéia de "mal" e, dessa forma, distanciam-se do "bem".

Manifestações de violência, desenvolvidas na segunda metade do séc. XX, como diferentes formas de fanatismo, terrorismo, crescimento da xenofobia, bem com ações de skinheads, traficantes de drogas, esquadrões da morte, neonazistas, booligans e serial killers, demonstrariam, para autores como Michel Mafessoli (2004, p. 13), “o fim de um ciclo; o ciclo que foi inaugurado com a consagração do bem como valor absoluto".

Existiria, a partir de então, uma perda do sentido atribuído aos valores "bondade" e "maldade". A "vivência do mal" passaria a ser admitida. A linha divisória entre os extremos do que deve ser buscado ("bem") e do que deve ser afastatado ("mal") teria perdido, sensivelmente, sua nitidez. O que é colocado em questão é a própria consistência ontológica da dual oposição entre "bem" e "mal", até então inquestionável. ${ }^{3}$

Crash não traz uma clara delimitação entre personagens que representam o "bem" e o "mal". Se são as atitudes desses personagens que possibilitam sua identificação dentro do jogo binário entre "mocinhos" e "bandidos", suas ações não deixam essa identificação aparecer claramente.

Os aparentes "bandidos" do filme se tornam capazes de ações louváveis e mesmo heróicas. O Oficial Ryan (Ryan Phillippe), após parar arbitrariamente o carro conduzido pelo diretor de TV Cameron (Terrence Howard) e agredir sexualmente sua esposa Christine (Thandie Newton), é capaz, no dia seguinte, de arriscar sua vida para

\footnotetext{
${ }^{3}$ O conceito de banalidade do mal, cunhado por Hannah Arendt (1999, p. 37), funda-se justamente na existência de um crescente processo de indistinção entre os valores de "bem" e "mal". Para a autora, o "bem" perderia, no contexto por ela estudado (julgamento do nazista Adolf Eichmann em Jerusalém), seu "peso ontológico", produzindo, como conseqüência, "um 'mal' sem rosto específico".
} 
retirar a mesma Christine de um carro em chamas. O jovem assaltante negro George (Ime Etuk), que leva a vida praticando roubos, como uma das últimas ações do filme, liberta um grupo de cambojanos, mantidos escravos, não obstante a proposta de troca por uma expressiva quantia em dinheiro.

Da mesma forma, os supostos "mocinhos" de Crash, ao final, são capazes de ações reprováveis. O Oficial Hanson (Matt Dillon), que passa todo o filme a lamentar ter entrado numa corporação (polícia de Los Angeles), marcada pelo preconceito e pela intolerância racial, ao fim, mata e esconde o corpo de um jovem negro, ao qual dera uma carona. $^{4}$

Para o novo paradigma da violência, a fragmentação do limite entre "bondade" e "maldade" explicar-se-ia pelo "esvaziamento de ideologias" tradicionais, que marcaram a maioria dos movimentos sociais, até então. O enfraquecimento, em todo o mundo, de mobilizações derivadas do marxismo-leninismo, anarquismo ou de extrema direita ${ }^{5}$ poria limites à "certeza do bem". A chamada "luta de classes" deixaria de ser um conceito de entendimento do/no mundo.

\footnotetext{
Não é mais a luta contra a exploração, a sublevação contra um adversário, que mantém com os atores sociais uma relação de dominação, e sim a não-relação social, a ausência de relação conflitual, a exclusão social; eventualmente carregada de desprezo cultural ou racial, que alimentam hoje a violência em toda parte do mundo (WIEVIORKA, 1997, p. 7).
}

Historicamente, a violência de grupos revolucionários ou de regimes nazifascistas, do séc. XX, teria como fundamento reivindicações e projetos predeterminados e seriam, assim, "instrumentais", no sentido de apontarem para uma finalidade futura, para a “(re)construção da História". O que ocorre contemporaneamente seria a "perda de uma

\footnotetext{
${ }^{4}$ Os exemplos citados não afastam Crash do moralismo que marca a produção hollywoodiana. Se por um lado o filme tenta quebrar a dualidade entre "bem" e "mal", mostrando, inclusive, que os conflitos surgidos não tiveram, ao final, uma solução - o caráter "cíclico" de seu desenlace, com uma nova batida que inicia novas discussões pautadas em intolerâncias, denota essa continuidade - , o moralismo está presente nas estórias de personagens que, diante de determinadas situações, "aprendem a lição", mudando seu comportamento. Assim é o caso de Jean Cabot (Sandra Bullock), que descobre em sua empregada Maria sua maior amizade, ou do assaltante negro George, que, após assaltar pela primeira vez outro negro, muda suas ações.

${ }^{5}$ Conceitos similares são formulados por Michel Mafessoli (2000, p. 111-115), quando trata do "vazio de sentidos", e por Jean Baudrillard (1994, p. 14-19), ao falar do "abismo de sentidos".
} 
pretensão política abstrata", de "uma razão histórica pela qual lutar e, caso necessário, morrer e matar". Ocorre a "transfiguração do político" (MAFESSOLI, 2004, p. 19). ${ }^{6}$

O "esvaziamento de ideologias" significa a impossibilidade de saber, a favor do quê ou de quem lutar e, por conseguinte, contra o que/quem agir. Significa não ter mais inimigos declarados, explícitos. Nesse estado, "o homem reina sozinho, mas sem uma razão final. Não tendo mais inimigo, fabrica-o desde de dentro [sic], do interior de si" (BAUDRILLARD, 2003, p. 56). A eleição de novos inimigos torna-se algo arbitrário, na mesma intensidade com que se torna possível a percepção de si próprio como único inimigo.

O filme Crash, tido por parte da crítica como uma espécie de auto-retrato da sociedade norte-americana pós-11 de setembro, serve como instrumento de análise de como tal sociedade reordenou sua concepção de "inimigo" após aqueles acontecimentos, ou mesmo de como, nesse processo, produziu novas representações sobre si mesma.

Uma das principais estratégias eleitas pelo governo norte-americano, após o atentado, foi identificar o "terrorismo" com a idéia de "mal supremo", e os "terroristas", personificados nas figuras de Osama bin Laden e Saddam Hussein, como "inimigos maiores". A Secretária de Estado Condoleezza Rice, então responsável pela administração da segurança da Casa Branca, afirmou que, "sendo Saddam Hussein uma entidade do mal, o mundo deveria nos ajudar [os EUA] a combatê-lo" (BAUDRILLARD, 2003, p. 32).

A principal característica desse "mal supremo" seria a irracionalidade. "São loucos suicidas, psicopatas, fanáticos de uma causa pervertida, eles mesmos manipulados por alguma potência maléfica, que se limita a explorar o ressentimento e o ódio dos povos oprimidos para aplacar a sua sede de destruição" (BAUDRILLARD, 2003, p. 26).

A (i)lógica do "terrorismo" teria suas bases na produção de uma "alteridade". Os inimigos, além de insanos, são "eles". Não podem, em nenhuma hipótese, serem confundidos como o "nós". Possuiriam uma historicidade e cultura específicas. Uma religião, um língua, vestimentas, objetivos e traumas, traçados paralela e independentemente da história norte-americana.

\footnotetext{
${ }^{6}$ Michael Hardt e Antônio Negri (2001, p. 383) entendem que o "Império", termo utilizado pelos autores para análise das consequiências geopolíticas da chamada "globalização", produz uma nova "ontologia da política". "O paradigma da medida é quebrado, indo de encontro ao que todos os teóricos até então o fizeram, a exemplo de Marx".
} 
O discurso de Jorge W. Bush, veiculado logo após o atentado, lembra a fala do personagem que representou o presidente norte-americano no filme Independence Day ${ }^{7}$. Na ocasião, Bush construiu a representação dos "terroristas", a partir de então, sinônimo de "islâmicos", como verdadeiros "alienígenas". Assim, como no referido filme, os responsáveis pelo 11 de setembro parecem ter vindo de outro planeta, sem qualquer relação com a Terra, com o único objetivo de exterminar a humanidade. Para Robert Kurz, em artigo escrito poucos dias após o atentado contra as Torres Gêmeas, esse papel de alienígena, à margem do planeta, à margem do capitalismo e da razão, pelo visto agora deverá ser assumido pelo islamismo militante, como se se tratasse de uma cultura estranha e recém-descoberta, revelando-se como ameaça sombria (KURZ, 2001, p. 14).

No entanto, Baudrillard entende que os atos terroristas, longe de se caracterizarem pela irracionalidade/alteridade, ligam-se à mesma lógica que ergueu e sustenta o "império norte-americano". O terrorismo faria parte da (i)lógica do capitalismo atual, favorecendo-o e mantendo direta relação com o novo paradigma da violência, que, no âmbito global, estaria ligado à perpetuação "de guerras sem sentido". "Quantas ações foram legitimadas pelo perigo terrorista? [...] Se não existisse o terrorismo, o sistema [capitalista] o inventaria" (BAUDRILLARD, 2003, p. 30-31).

A eficácia do terrorismo, para Baudrillard, reside em sua capacidade de produzir a sensação de terror. O sonho da "integração global" levaria essa sensibilidade ao extremo. Se tudo está interconectado e os limites do tempo e espaço já foram há muito relativizados, então o terror já é, também, global. Qualquer catástrofe, seja de ordem técnica ou mesmo natural, passa a ser potencialmente "terrorista".

O terrorismo, igualmente, não seria "inaugural”, pois não inventa nada. Os terroristas não são alienígenas que trazem, de fora, desordem para dentro da "ordem mundial", pois essa "ordem" já está prenhe de desordem. ${ }^{8} \mathrm{O}$ "terror" apenas leva as idéias de insegurança e morte ao extremo, causando o assassínio de uma sociedade em fase

\footnotetext{
${ }^{7}$ Baudrillard (2003, p. 68-69) lembra que diretores de Hollywood, alguns deles produtores de Independence Day, foram contratados pelo governo norte-americano, após o atentado, como Conselheiros de Estratégias Anti-terror.

8 "Se o objetivo do terrorismo é desestabilizar a ordem mundial exclusivamente pelas suas forças, então ele é absurdo; a relação de forças é tão desigual - e, de qualquer maneira, já há tanta desordem nessa ordem mundial e tanta desregulação - que é inútil tentar produzir mais” (BAUDRILLARD, 2003, p. 28).
} 
terminal, ou mesmo já morta. O terrorismo, para Baudrillard, não é nada mais do que "a morte contra a morte".

No filme Crash, a sociedade norte-americana é representada como morta. A morte não decorre da ação de um inimigo externo, deriva de um processo de autodestruição que faz os americanos, em atos cotidianos, matarem-se mutuamente. O filme retrata 36 horas nas quais, através de diferentes estratégias, os personagens procuram diminuir-se ,moralmente, ou mesmo eliminarem-se, fisicamente.

Os diferentes conflitos são interpretados pelo personagem Graham, logo no início do filme, como uma espécie de busca por sensibilidade. "E suamos sempre atrás de metal e vidro. Acho que sentimos muito a falta do toque. Damos encontrões uns nos outros para sentirmos alguma coisa".

Percebendo-se morta, a sociedade norte-americana (re)inventa formas de produzir algum sentido, na dual acepção da palavra. Sentido como "sensação". Sentido como "objetivo".

Como sociedade que convive, ao mesmo tempo, sob os perigos do "terror" e da "falta de sensibilidade", os americanos procuram um novo entendimento de si mesmos. Buscam (re)delimitar quem eles são (o que se tornaram) após o atentado de 11 de setembro. Ao fim de um dos diálogos do filme, o Oficial Ryan pergunta ao policial Hanson: "você acha que sabe realmente quem você é? Você não sabe quem é!".

Jean Baudrillard entende que a sociedade norte-americana, num processo de auto-reflexão pós-atentado, aos poucos vai tomando uma nova conotação de si mesma. Vai transformando o inimigo externo em um inimigo interno, invisível e silencioso, que se confunde com aquela própria sociedade.

Passa a eleger, tal sociedade, a "compaixão" como valor supremo, crendo-se flagelada por Deus. Cria-se “a compaixão como paixão nacional de um povo que se pretende só com Deus e prefere se ver, antes como vítima de Deus, que de uma potência maléfica qualquer. God bless America tornou-se: 'enfim Deus nos atacou'” (BAUDRILLARD, 2003, p. 32). 
A "alteridade" terrorista converte-se na "autoria" do terror. Num ato de extremo egocentrismo ${ }^{9}$, os norte-americanos atribuem, a si próprios, o atentado terrorista. O 11 de setembro aparece como auto-flagelo.

\begin{abstract}
A irmã gêmea da compaixão (tão gêmea quanto as duas torres) é a arrogância. Chora-se por si mesmo, ao mesmo tempo em que se é o mais forte. Aquilo que nos dá o direito de ser os mais fortes é o fato de sermos, a partir de agora, as vítimas. É o álibi perfeito, toda a higiene mental da vítima, através do qual se elimina toda a culpa, o que permite, de alguma maneira, usar a infelicidade como um cartão de crédito (BAUDRILLARD, 2003, p. 33).
\end{abstract}

No auge da arrogância, difunde-se a "teoria da farsa", de grande repercussão entre cientistas políticos nos EUA. O atentado teria sido um plano, executado pela CIA, para legitimar ações do governo norte-americano que, naquela ocasião, passava por um momento de grande impopularidade.

\title{
ATOMIZAÇÃO, AUTISMO, PRESENTEÍSMO
}

A violência se encontra pulverizada em Crash. Os personagens desenvolvem ações de preconceito e intolerância, derivadas de conflitos cotidianos. Não há "grandes causas" pelas quais lutar ou "grandes inimigos" contra os quais guerrear. A guerra se faz de forma fragmentada, derivando de problemas individuais.

Na concepção de Hans Magnus Enzensberger (1995, p. 7-9), as manifestações violentas, hoje presentes, se encontram pulverizadas, sendo perceptíveis apenas se observadas em sua "molecularidade". Vivemos, para esse autor, desde o pós-Guerra Fria, uma "guerra civil molecular". 10

O termo "guerra civil" é empregado com vistas a afastar o que Enzensberger entende como a tradicional visão que possuímos da guerra, cunhada no séc. XIX e atrelada a conflitos entre Estados, onde "os adversários estão bem delimitados e identificados e as regras do conflito preestabelecidas". Para Enzensberger, a guerra entre Estados tornou-se a regra do conflito. A guerra civil, ou seja, a "guerra entre iguais", tornou-se exceção à regra, sendo identificada como forma irregular de conflito.

\footnotetext{
9 “A sociedade americana não quer reconhecer a sí própria no espelho do terror; na verdade, sob a impressão do horror, ela se torna mais presunçosa, mesquinha e irrefletida que antes" (KURZ, 2001, p. 14).

${ }^{10}$ Michel Wieviorka prefere o termo violência atomizada (1997, p. 19).
} 
$\mathrm{O}$ adjetivo "molecular" relaciona-se ao espraiamento da violência em grandes núcleos urbanos. Liga-se a formas microscópicas de conflitos que se caracterizam pela imprevisibilidade de eclosão e pela indeterminação de seus autores.

Dela [guerra civil molecular] não participam apenas terroristas e agentes secretos, mafiosos e skinheads, traficantes de drogas e esquadrões da morte, neonazistas e seguranças, mas também cidadãos discretos que à noite se transformam em booligans, incendiários, dementes violentos e serial killers (ENZENSBERGER, 1995, p. 15).

Além de fragmentada, a "guerra civil" seria imprevisível, pois ameaça começar continuamente, a todo instante.

Como já referido, a mudança paradigmática da violência seria produzida (por) e produtora de um "esvaziamento das ideologias". Ante tal esvaziamento, ações violentas deixariam de ser "instrumentais", no sentido de se dirigirem a alguma finalidade. A violência seria agora "não-instrumental"11.

O que se dá é a perda da necessidade de legitimação de ações violentas. Não se atribui mais o matar ou morrer a um ideal. Nessa interpretação, "esvaziou-se a legitimidade; a violência libertou-se completamente de fundamentações ideológicas" (ENZENSBERGER, 1995, p. 16). Haveria antes, para o autor em comentário, uma "necessidade em justificar", hoje, imperaria uma "ausência de convicção".

$\mathrm{O}$ esvaziamento de motivos gera o que Michel Wieviorka denomina de "violência pela violência". Ei-lo que diz: "Nos casos extremos, ela [violência] parece autonomizar-se, tornar-se um fim em si, lúdica, puramente destruidora ou auto-destruidora" (WIEVIORKA, 1997, p. 12). E, mais:

\begin{abstract}
Sob vários aspectos, há a violência gratuita, lúdica, eventualmente ligada ao gosto do risco, a um desejo de aventura, ao esforço para produzir ou atingir um acréscimo de sentido também relacionado com este nível, bem como aquele que constitui o contrário da busca de sentido, e implica muito na abolição de qualquer tipo de sentido no puro prazer de uma violência desenfreada (WIEVIORKA, 1997, p. 32).
\end{abstract}

\footnotetext{
${ }^{11}$ A concepção de que poderiam existir formas de violência não-instrumentais, ou seja, despidas de quaisquer finalidades, parece ser, ao menos no âmbito terminológico, desacreditada por Hannah Arendt. Isso porque, para a autora, o próprio conceito de violência passa, necessariamente, pela idéia de ser ela a mediação para se alcançar alguma finalidade. Nesse aspecto, comentando o pensamento de Arendt, André Duarte destaca que "a violência seria puramente instrumental, ou seja, não é mais que um meio para atingir determinado fim através da coerção. Em suma, enquanto o poder se exerce pelo estabelecimento de pactos e consensos transitórios, que não eliminam a possibilidade de divergência e mesmo do conflito violento, a pura violência enquanto tal se impõe de modo a calar os opositores de destruir a pluralidade dos participantes da cena pública" (DUARTE, 2004, p. 36).
} 
A não-instrumentalidade da violência, para a mesma vertente, aproxima-se demasiadamente da vontade de negação/destruição do outro, ou de si mesmo (autodestruição). Há, para Hans Enzensberger (1995, p. 24), um caráter “autista” em tais comportamentos, onde "viver ou morrer é a mesma coisa" e a "autodestruição não é um subproduto inevitável, e sim o objetivo de fato". Da mesma forma, Wieviorka (1997, p. 37) afirma que "a violência, em lugar de expressar em vão aquilo que a pessoa ou o grupo aspiram afirmar, torna-se pura e simples negação da alteridade e, ao mesmo tempo, da subjetividade daquele que a exerce".

Crash retrata o "autismo" da sociedade norte-americana que, num contexto póstraumático (pós-atentado), perderia a capacidade de criar critérios claros na delimitação de sua intolerância. O filme retrata uma série de atitudes preconceituosas que negam a si mesmas. $\mathrm{O}$ que, num primeiro momento, parece ser a razão de determinando preconceito, logo em seguida, inverte-se. Pólos aparentemente inconciliáveis aproximam-se

Dois exemplos. No dia seguinte ao qual o Oficial Ryan demonstra preconceito com um casal de negros, elege como novo parceiro o Oficial Gomez (Eddie J. Fernandez), um hispânico. Da mesma forma, Jean Cabot, que inicia o filme insultando um chaveiro mexicano, desconfiando de sua honestidade e o adjetivando de gângster, acaba, ao fim, confessando que sua melhor amiga é Maria, também hispânica.

Esse jogo de aproximação/repulsa enfatiza a própria falta de limites das representações formuladas contra indivíduos ou grupos, vítimas da intolerância. Saber o que não se "tolera", em Crash, torna-se algo difícil. Os estereótipos se confundem facilmente. Para Graham, no diálogo com Ria, alguém nascido em Porto Rico ou El Salvador é, da mesma forma, um "mexicano". O Promotor Rick (Brendan Fraser) afirma a seu assessor que "árabe e negro parecem ser a mesma coisa", podendo muito bem um passar pelo outro.

Por outro lado, parece que a sociedade norte-americana aprendeu a "jogar" com a falta de critérios na identificação de seus preconceitos. Em Crash, a todo o momento, os estereótipos, objetos de intolerância, são (re)inventados e (re)apropriados. Os preconceitos tornam-se produtos comerciais. No filme, dirigido pelo personagem Cameron, os produtores tentam construir um "negro" padrão, com sua vestimenta e forma de falar 
peculiar. Ao pronunciar frase que se distancia dessa "padronização", o "negro" é chamado a, novamente, encenar o diálogo. ${ }^{12}$

A fragilidade dos estereótipos que supostamente sustentam os atos de violência e negam qualquer tipo de lógica que pudesse ser atribuída a essas ações, possibilita o questionamento da existência, no filme, de uma violência instrumental.

A (i)lógica dessas ações seria simplesmente a negação da alteridade ou, retornando à expressão do detetive Graham, serviriam para que uma sociedade despida de sensibilidade promovesse, cotidianamente, "encontrões e brigas" para lembrar que ainda está viva.

O novo paradigma da violência seria ainda marcado pelo "presenteísmo". Nesse contexto, o tempo presente seria eleito como único ponto de referência na determinação das ações dos indivíduos. Para Mafessoli (2004, p. 166):

É neste laboratório que se forma um corpo social indiferente às grandes maquinarias institucionais completamente voltadas para o futuro, mas atento ao "interesse do presente" em todas as suas modulações [...]. O sentimento trágico da vida presenteísta nada tem de estático. Tampouco se trata, como queriam crer certos espíritos apressados, de uma canonização do status $q u o$, mas de um processo ascendente a partir do vácuo.

O futuro aparece como perpetuação do presente. O tempo se torna cíclico. A colisão do veículo da atendente Shaniqua, ocorrida no final do filme, ao reproduzir situação similar ao início dos acontecimentos (batida entre o carro onde estavam os detetives Graham e Ria e o veiculo dirigido por Kim Lee), não apenas dá uma conotação de continuidade aos conflitos que marcam o filme, mas passa também a idéia do início de um novo ciclo de problemas, que acabará em uma nova batida, e assim por diante.

O abandono da idéia de futuro como algo a ser perseguido, posto que passível de transformação, faz com que os atos de destruição cheguem ao extremo. Norbert Elias, ao estudar manifestações violentas de grupos guerrilheiros (nazistas), na Alemanha do período que antecede a $2^{\mathrm{a}}$ Guerra Mundial, afirma que

Um papel central é desempenhado pelo sentimento de que a sociedade em que se vive é totalmente desprovida de significação e valor. A única esperança de uma vida mais perfeita, mais significativa, reside na destruição dessa sociedade. Nessa situação, a destruição pode

\footnotetext{
${ }^{12}$ A presença, no roteiro do filme Crash, de um filme dirigido por Cameron, pode ser percebida como uma espécie de (auto)crítica à Hollywood. Aliás, a cidade cujos conflitos e preconceitos são postos em questão é Los Angeles, na qual de localiza os estúdios da produção hollywoodiana.
} 
facilmente tornar-se um fim em si. Deixa de se pensar sobre o que deve realmente acontecer depois. O que só muito marginalmente interessa é a questão de saber que aspecto teria uma outra sociedade, que prometa dar à vida um nível mais elevado de significação. Todas as tramas e maquinações giram em torno do presente, todo o planejamento do próximo ato de violência e a constante necessidade de escapar às autoridades (ELIAS, 1997, p. 206).

O ideal de destruição em uma sociedade que nega a alteridade faz com que os atos destrutivos se voltem contra essa mesma sociedade. Em diferentes trechos de Crash, quando querem impor algum tipo de respeito, os personagens afirmam serem "cidadãos norte-americanos". Essa afirmação não produz qualquer efeito. Todos são cidadãos norteamericanos: negros, coreanos, iranianos, hispânicos...

\section{CONSIDERAÇÕES FINAIS}

O novo paradigma da violência é uma crítica aos limites da modernidade. $\mathrm{O}$ suposto fracasso do Estado moderno derivaria da atual impossibilidade de resolver conflitos e de impor algum tipo de ordem junto à sociedade.

O esvaziamento de ideologias seria resultado da impossibilidade de instituições modernas, como o Estado, continuarem alimentando, na sociedade, valores por algum tempo tidos como dignos de defesa. A "explosão da violência" apareceria como negação de instituições despidas de sentido, que não mais conseguem propagar nexos para a vida, notadamente para a juventude.

A ação de jovens que atuam nas mais diferentes formas de violência urbana é movida pela própria busca de sentido do viver e pela negação de instituições modernas, como o Estado.

Se um considerável número de jovens teve sufocada suas oportunidades de expressão [...], um potencial explosivo, sob condições favoráveis, encontrará repercussão, repetidas vezes, em movimentos que se colocam em pronunciada oposição às instituições políticas estabelecidas (ELIAS, 1997, p. 186).

Da mesma forma, Michel Wieviorka (1997, p. 23) entende que a violência como "forma de produção do sentido", converte-se na tentativa de "produzir por meios próprios aquilo que antes lhe era dado pela cultura ou pelas instituições". 
A violência se aparta de projetos ideológicos - dentre os quais o maior seria a própria defesa de legitimidade do Estado - e converge para a idéia de negação das instituições.

Os criminosos de hoje não necessitam de rituais, manifestações públicas, uniformes, programas, incitamento ou juramento de fidelidade [...]. O ódio é suficiente. Se o terror era um monopólio dos regimes totalitários, hoje ele reaparece independente do Estado (ENZENSBERGER, 1995, p. 23).

A interpretação de que as manifestações hodiernas, de violência, derivam de um rompimento histórico sem precedentes (ruptura) deve, a meu ver, ir além de um discurso que se vale de exemplos cotidianos para afirmar que hoje, e a cada dia mais, atingimos um "grau de violência sem precedentes".

Tal reflexão deve contribuir, nesse sentido, para a análise dos limites de instituições modernas, em organizar a sociedade e, sobretudo, em (re)construir sentidos de existência para indivíduos e grupos sociais.

Violência é, de qualquer forma, "manifestação", mesmo que atrelada a interesses auto-destrutivos. Ainda quando desvinculada de movimentos "organizados", é estratégia de afirmação ou reivindicação, ou, simplesmente, de diversão.

\section{REFERÊNCIAS BIBLIOGRÁFICAS}

ARENDT, Hannah. Eichmann em Jerusalém: um relato sobre a banalidade do mal. São Paulo: Companhia das Letras, 1999.

BAUDRILLARD, Jean. ____ Power inferno. Porto Alegre: Sulina, 2003.

CRASH: no limite. Produção e direção: Paul Haggis. Los Angeles: Lions Gate Films/Imagem Filmes, 2006. 1 DVD.

DUARTE, André. Modernidade, biopolítica e violência: a crítica arendtiana ao presente. In. DUARTE, André et al. (org.). A banalização da violência: a atualidade do pensamento de Hannah Arendt. Rio de Janeiro: Relume Dumará, 2004. p. 35-54.

ELIAS, Norbert. Os alemães: a luta pelo poder e a evolução do habitus no século XIX. Rio de Janeiro: Zahar, 1997.

ENZENSBERGER, Hans Magnus. Guerra civil. São Paulo: Companhia das Letras, 1995. 
HARDT, Michael; NEGRI, Antonio. Virtualidades. In. Império. 3. ed. Rio de Janeiro: Record, 2001, p. 376-391.

KURZ, Robert. O ímpeto suicida do capitalismo. Folha de São Paulo. São Paulo, 30 set. 2001, Mais!, p. 14-15.

MAFESSOLI, Michel. A parte do diabo. Rio de Janeiro: Record, 2004.

O tempo das tribos: o declínio do individualismo nas sociedades de massa. 3. ed. Rio de Janeiro: Forense Universitária, 2000.

WIEVIORKA, Michel. O novo paradigma da violência. Tempo Social, São Paulo, v. 9, n. 1, p. 5-41, maio 1997. 